Document downloaded from:

http://hdl.handle.net/10251/95453

This paper must be cited as:

Payri, R.; F.J. Salvador; Gimeno, J.; Novella Rosa, R. (2011). Flow regime effects on noncavitating injection nozzles over spray behaviour. International Journal of Heat and Fluid Flow. 32(1):273-284. doi:10.1016/j.ijheatfluidflow.2010.10.001

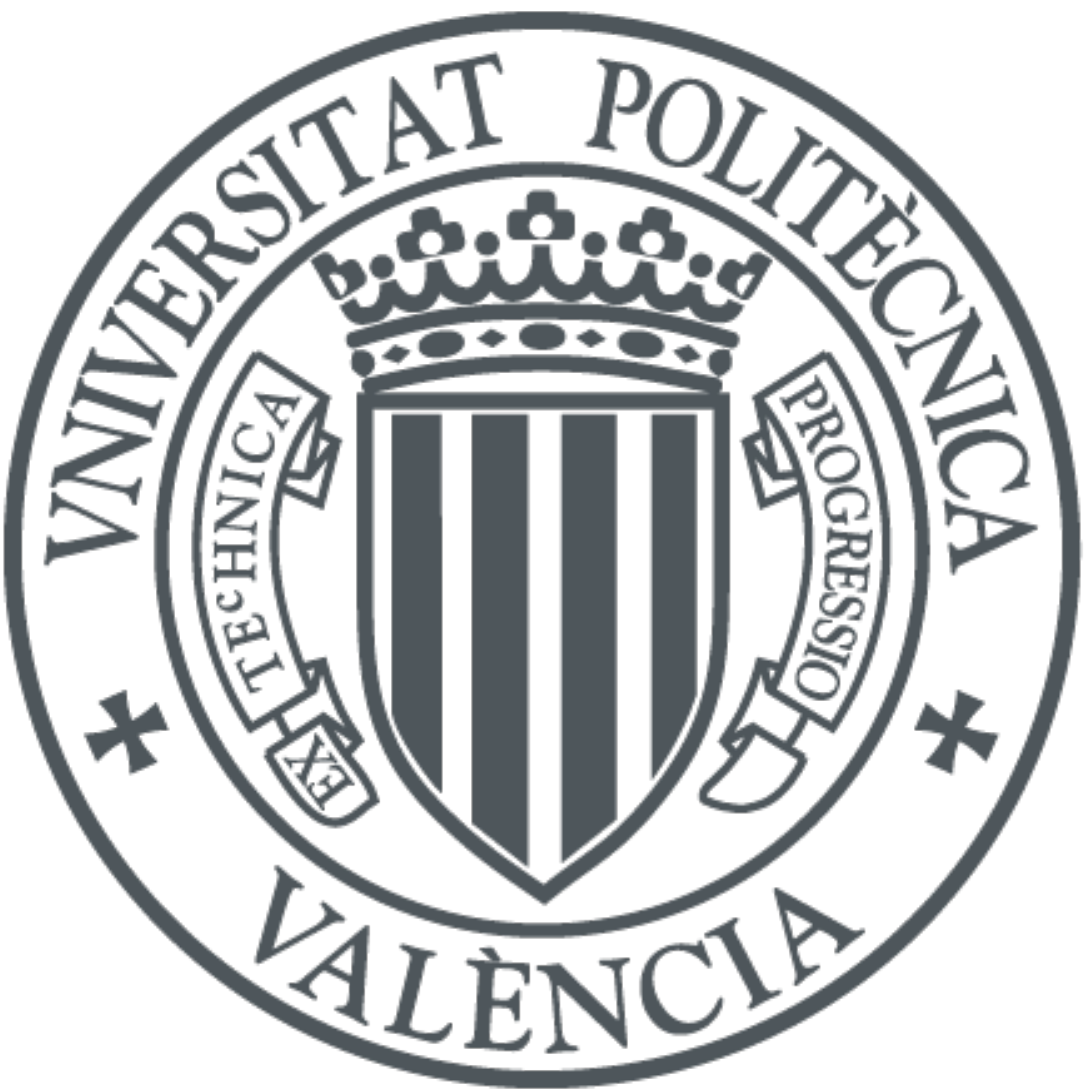

The final publication is available at

http://doi.org/10.1016/j.ijheatfluidflow.2010.10.001

Copyright ELSEVIER SCIENCE INC

Additional Information 


\title{
Flow regime effects on non-cavitating injection nozzles over spray behavior
}

\author{
R. Payri, F.J. Salvador, J. Gimeno, R. Novella \\ CMT-Motores Térmicos, Universitat Politècnica de València, Camino de Vera s/n, Valencia \\ E-46022, Spain
}

\begin{abstract}
This paper deals with the influence of flow regime (laminar, transition or turbulent) on the internal flow behavior, and how it affects the spray development in diesel nozzles. In particular, the research described here aims at studying and quantifying the internal flow regime effects on the spray behavior. With this purpose, internal flow results, based on mass flow rate and momentum flux measurements performed on three different tapered nozzles and which helped to determine the flow regime, has been taken into account as a point of departure for the spray behavior analysis. Thus, in this work, spray macroscopic visualization tests have been performed and analyzed which clearly revealed a change in the behavior of the angle and penetration of the spray related to the change of the flow nature. Moreover, with all the experimental data available, it has been possible to relate macroscopic parameters of the spray with those describing the internal flow (momentum and effective velocity) or the geometry of the nozzle (length or diameter) through correlations.
\end{abstract}

Keywords: Diesel injection, flow regime, turbulence

Cite as:

R.Payri, F.J.Salvador, J.Gimeno, R.Novella, "Flow regime effects on non-cavitating injection nozzles over spray behavior", International Journal of Heat and Fluid Flow, (2011), Vol. 32, pp. 273-284, doi:10.1016/j.ijheatfluidflow.2010.10.001 


\section{Notation}

$A_{\text {ef }}$ Effective area.

$A_{o}$ Orifice outlet section area.

$C$ Spray penetration adjustment constant.

$C_{a}$ Area Coefficient.

$C_{d}$ Discharge coefficient.

$C_{v}$ Velocity coefficient.

$D_{i}$ Inlet diameter.

$D_{o}$ Outlet diameter.

$D_{e f}$ Effective diameter.

$k_{i}$ Initial zone spray penetration constant.

$k_{p}$ Developed zone spray penetration constant.

$L$ Orifice length.

$\dot{M}$ Momentum flux in axial direction.

$\dot{m}$ Mass flux.

$p_{b}$ Back pressure.

$p_{i}$ Injection pressure.

$r$ Inlet curvature radius.

Re Reynolds number.

$S$ Spray penetration.

$t$ Time.

$t_{r}$ Transition time between initial and developed spray zones.

$t_{o i}$ Origin time correction for fitting penetration in the initial spray zone. 
$t_{o p}$ Origin time correction for fitting penetration in the developed spray zone.

$u_{e f}$ Effective velocity.

$\Delta p$ Pressure drop across the nozzle.

$\rho_{a}$ Discharge gas density.

$\rho_{f}$ Fuel density.

$\theta$ Spray angle.

\section{Introduction}

One of the diesel engine components that most interest has arisen in recent years has been the injection system. This interest is not accidental, since the quality of the air-fuel mixture, and in turn, the engine performance and pollutant emissions depend fundamentally on the proper operation of this system, more so given the increasing engine pollutant control requirements.

Undoubtedly, if one intends to improve the performance of the injection system and the subsequent combustion, one must first deeply understand all the phenomena involved in the own process of injection and atomization of the spray Som and Aggarwal (2009); Payri et al. (2009); Park et al. (2009c,a,b); Ramírez et al. (2009).

As a result of the operating conditions, including high injection pressures which result in a extremely high spray exit velocity, the characteristics of the spray correspond to the latest spray regimes defined by Reitz and Bracco Reitz and Bracco (1979), and mainly in the known as the atomization regime, which is characterized by the atomization of the spray beginning just outside the hole. Especially for this regime, the mechanisms that cause the breakdown of the liquid vein are not fully understood or even known. Despite numerous experimental studies, there is currently no one theory that can explain all observed behaviors. Thus, due to the high spray velocities, mechanisms other than the aerodynamic interaction such as turbulence, cavitation, etc.. begin to appear. The exact role of these mechanisms is not well known and they can vary depending on operating conditions. Thus, the atomization will be caused by the superposition of these independent mechanisms and, depending on injection conditions, they can charge more or less relative importance. Within these mechanisms, some authors like Ruiz Ruiz (1998) have described the turbulence as one of the major causes of atomization. Such turbulence is generated in the injection system, particularly in the 
injector orifice. The radial turbulent velocities in this section are contained by the walls of the injector. At the exit of the nozzle, the radial component of turbulent fluctuations eject part of the fuel outside the fluid vein, causing atomization. This mechanism can explain the fragmentation of sprays injected into the vacuum, for which there is no aerodynamic interaction with the environment. On the other hand, this is clearly not the unique mechanism of atomization of a diesel spray because it is unrelated to the increased atomization of the spray when increasing gas density.

The objective of this work is to study the influence of flow regime, laminar, transition or turbulent on the internal flow behavior, and how it affects the development of the spray.

In order to do this, an experimental study has been performed using three convergent nozzles with different diameter, where tests of spray macroscopic visualization have been obtained and analyzed, clearly observing a change in the behavior of the angle and the penetration of the spray related to the change of the flow regime. Furthermore, from all information available, it has been possible to relate the parameters of the spray with those of the internal flow (which take into account the flow regime) through correlations.

The use of convergent nozzles is justified precisely because the convergence of the holes will prevent the onset of cavitation phenomenon, which leads to study the effect of turbulence without being masked by the influence of cavitation in the spray. Moreover, in recent years, engine manufacturers are opting for this type of nozzles instead of the cavitating nozzles with cylindrical holes Soteriou et al. (2006), so this study will help to improve the knowledge about the behavior of spray in non-cavitating conditions.

Apart from nozzle geometry and test conditions, this work uses as input data the internal flow characterization of the studied nozzles. This characterization consist of the measurement of not only the mass flow rate but also the momentum flux. The great interest of this measure is that, along with the mass flow rate measurement, different parameters can be estimated as interesting as the velocity and the effective area at the exit of the injection orifice, and the respective dimensionless coefficients. Using these parameters, it has been determined what was the flow regime at each tested point.

Along the study of the injected spray, the measure of momentum flux is not only useful because it allows a deep characterization of the internal flow, but also the own behavior of the spray is controlled by this momentum flux, as determined by numerous studies on jets Hay and Jones (1972). Thus, to complement and as an aid to the analysis, a characterization model of the spray is presented just based 
on the momentum flux. This model will be used in subsequent analysis of the results obtained by means of the visualization tests.

The present article is divided into three parts. In the first part the penetration model used in the article is presented (Section 2). The second part sets out the nozzles and operating conditions tested (Section 3), and the experimental techniques employed (Section 5). Finally, in the last part the results obtained are presented (Section 6), and then analyzed and discussed (Sections 7 and 8).

\section{Modeling of the spray penetration by means of the momentum flux}

The model used to characterize the penetration of the spray is similar than that proposed by Naber and Siebers Naber and Siebers (1996), but with slight modifications. This model distinguishes between two regions of different behavior: initial or transient, characterized by a linear behavior of penetration with time $S \propto t$; and the region of fully developed spray where the penetration behaves proportional to the square root of time $S \propto \sqrt{t}$. The expression proposed by Naber and Siebers takes into consideration these two regions:

- If $t<t_{r}$ :

$$
S(t)=C_{v} \sqrt{\frac{2 \Delta p}{\rho_{f}}} t
$$

- If $t \geq t_{r}$ :

$$
S(t)=\frac{C_{v}^{1 / 2}\left(2 C_{a}\right)^{1 / 4}}{(a \tan \theta / 2)^{1 / 2}} \rho_{a}^{-1 / 4} \Delta p^{1 / 4} D_{o}^{1 / 2} t^{1 / 2}
$$

where

$$
t_{r}=\frac{\left(2 C_{a}\right)^{1 / 2}}{C_{v} a \tan \theta / 2} \frac{\rho_{f} D_{o}}{\left(\rho_{a} \Delta p\right)^{1 / 2}} .
$$

According to these equations, it is evident how in the transient zone: $S$ is linear with time $t$, an increase of $\Delta p$ (or injection velocity) increases penetration, and finally neither $\rho_{a}$ nor $D_{o}$ affect penetration. However, looking at the equation for the fully developed zone: $S$ becomes proportional to $t^{1 / 2}$, an increase of $\Delta p$ increases penetration, an increase of $\rho_{a}$ decreases penetration, an increase of $D_{o}$ increases penetration and finally, an increase of spray angle $\theta$ leads to a shorter spray.

The evolution of the penetration in these zones has been previously observed by a great number of authors Naber and Siebers (1996); Hiroyasu and Arai (1990); 
Payri et al. (2005, 2007). Although various authors proposed a first transient phase for the penetration law in which penetration is linear with time, there is not a general agreement in its origin. Thus, Hiroyasu and Arai Hiroyasu and Arai (1990), justify this phase arguing that in the first instants the spray is not fully atomized yet, the liquid vein is not broken and the spray do not have the cone shape and, as a result it penetrates with a constant velocity. On the other side, Naber and Siebers Naber and Siebers (1996) justify this initial stage considering that in the first instants the spray penetration is ruled by the injected fuel, whereas in the next phase it is controlled by the entrained air. The third explanation, proposed by different authors Wan and Peters (1999); Payri et al. (2005, 2007), is based on assuming that this first initial phase of the spray is related to the initial transient behavior that could appear in the injection rate. Although, evidently a relatively long transient stage in the injection rate will affect the penetration law, this not seems to be the unique mechanism that splits the penetration behavior into two phases. Thus, suspecting the effect of injection rate, Naber and Siebers Naber and Siebers (1996) measured experimentally this transient stage, concluding that it was too short to justify their results.

The reason for selecting this model is because, unlike others such as those proposed by Hiroyasu and Arai Hiroyasu and Arai (1990) or Wakuri et al. Wakuri et al. (1960), this one takes into account internal flow parameters closely related to the momentum flux such as the contraction area and velocity coefficients. In fact, Naber and Siebers Naber and Siebers (1996) use the momentum flux measurement for calculating these coefficients in the same way as in the present work.

These expressions come from considering the momentum flux and the effective velocity, in the expressions for the fully developed and the initial spray regions respectively. Indeed, knowing that the momentum flux can be expressed as $\dot{M}=C_{a} C_{v}{ }^{2} 2 A_{o} \Delta p$, the equation (2) can be written as

$$
S=k_{p}\left(\tan \frac{\theta}{2}\right)^{-1 / 2} \rho_{a}^{-1 / 4} \dot{M}^{1 / 4} t^{1 / 2},
$$

in which the two coefficients $C_{a}$ and $C_{v}$, the orifice diameter $D_{o}$ and the pressure difference $\Delta p$, are included together in the value of momentum flux, $\dot{M}$. In this expression, the penetration constantDesantes et al. (2005) $k_{p}$, has been added, replacing the constant $a$ used in equation (2). The equivalence between these two constants is $a=1 /\left(k_{p}{ }^{2} \sqrt{\pi}\right)$.

Desantes and others Desantes et al. (2006), combining a theoretical development with an experimental verification, obtained a value for the penetration constant of $k_{p}=1.26$, being this value independent of both the injection conditions 
and the geometry of the injection nozzle.

For the initial zone, the expression (5) will be used. This relation was obtained from equation (1), knowing that the effective velocity can be expressed as $u_{e f}=$ $C_{v} \sqrt{2 \Delta p / \rho_{f}}$.

$$
S=k_{i} u_{e f} t
$$

A new constant $k_{i}$ has been added in this equation. According to Naber and Siebers Naber and Siebers (1996), the value of this constant may depend on the opening speed of the injector. This constant does not appear in equation (1) because in the tests conducted by Naber and Siebers, the injector opening time is negligible, therefore $k_{i}=1$.

Finally, the transition time between the initial and the fully developed zones in terms of momentum flux and effective velocity is obtained operating with the above relations

$$
t_{r}=\frac{k_{p}^{2}}{k_{i}^{2} \tan \theta / 2} \frac{\sqrt{\dot{M}}}{\sqrt{\rho_{a}} u_{e f}^{2}} .
$$

\section{Nozzle description and test plan}

\subsection{Nozzle description}

To perform this study it has been chosen three different one hole axi-symmetric nozzles. The orifices are convergent with conical shape, additionally, the nozzles have been manufactured with an aggressive hydroerosion process to round the edges of orifice inlet providing them an inlet radius $r$ large enough to avoid separation of the boundary layer at the orifice inlet. Both characteristics, convergent orifices and large inlet radius, will prevent the cavitation phenomenonMacián et al. (2003b).

On these nozzles, the silicone mold technique has been used Macián et al. (2003a) with the aim of obtaining the internal geometry of orifices. Results for three nozzles are summarized in Table 1, while the characteristic of nozzles dimensionless geometric parameters are shown in Table 2. Unfortunately it has not been possible to obtain the complete mould for nozzle C, so $D_{o}$ value used in the current research is the supplied by nozzle manufacturer.

As it is shown in these tables, the three nozzles are similar. The unique difference between them is the orifice diameter. It is noteworthy as relevant nozzles characteristics, the strong orifices convergence and the great inlet radius. 
Table 1: Internal geometry of the studied one-hole nozzles.

\begin{tabular}{lcccccc}
\hline Nozzle & $r$ & $D_{i}$ & $D_{m}$ & $D_{o}$ & $k$-factor & $A R$ \\
& $\mu \mathrm{m}$ & $\mu \mathrm{m}$ & $\mu \mathrm{m}$ & $\mu \mathrm{m}$ & - & $\%$ \\
\hline $\mathrm{A}$ & 42 & 140 & 125 & 112 & 2.8 & 36.0 \\
$\mathrm{~B}$ & 47 & 167 & 145 & 138 & 2.9 & 31.7 \\
$\mathrm{C}$ & 49 & 195 & & 156 & 3.9 & 36.0 \\
\hline
\end{tabular}

Table 2: Dimensionless parameters of the studied one-hole nozzles.

\begin{tabular}{lcccc}
\hline Nozzle & $D_{o}$ & $L / D$ & $r / D$ & $D_{i} / D_{o}$ \\
\hline $\mathrm{A}$ & $112 \mu \mathrm{m}$ & 8.93 & 0.30 & 1.25 \\
$\mathrm{~B}$ & $138 \mu \mathrm{m}$ & 7.25 & 0.28 & 1.21 \\
$\mathrm{C}$ & $156 \mu \mathrm{m}$ & 6.41 & 0.25 & 1.25 \\
\hline
\end{tabular}

\subsection{Test plan}

In the study of spray injection, one of the parameters that affect the behavior of the spray is the density of gas in which it is injected Hay and Jones (1972), so that this density will be one of the parameters to be controlled. This forces to maintain temperature control and achieve the change in density by varying the discharge pressure.

The test plan selected for this study consists of three injection pressures and five gas discharge densities, achieved through five different discharge pressures. The gas temperature has remained constant at $33^{\circ} \mathrm{C}$. The energizing time is set at $2000 \mu$ s, more than enough time to study the spray taking into account that the measurement range is limited to about $65 \mathrm{~mm}$. Data from the test plan are:

$$
\begin{array}{ll}
\text { Injection pressure } & 30-80-130 \mathrm{MPa} \\
\text { Gas density } & 10-15.5-25.4-32.5-40 \mathrm{~kg} / \mathrm{m}^{3} \\
\text { Back pressure } & 0.81-1.31-2.21-2.85-3.53 \mathrm{MPa} \\
\text { Energizing time } & 2000 \mu \mathrm{s}
\end{array}
$$

To perform the different analysis that relates the internal flow with the spray it is necessary to know the internal flow parameters. In Appendix A there is the internal flow data used in this study.

\section{Spray momentum test rig}

With this experimental equipment it is possible to determine the impingement force of a spray on a surface. This force is equivalent to the spray momentum 
flux. Figure 1 shows a sketch of the momentum test rig. Sprays are injected into a chamber that can be pressurized with nitrogen up to $8 \mathrm{MPa}$ in order to simulate pressure discharge conditions that are representative of actual pressure conditions inside the engine combustion chamber during the injection process. With the aim of improving the quality of the experimental data, these tests were performed considering long injection events, reaching in all cases steady state conditions in terms of constant momemtum flux.

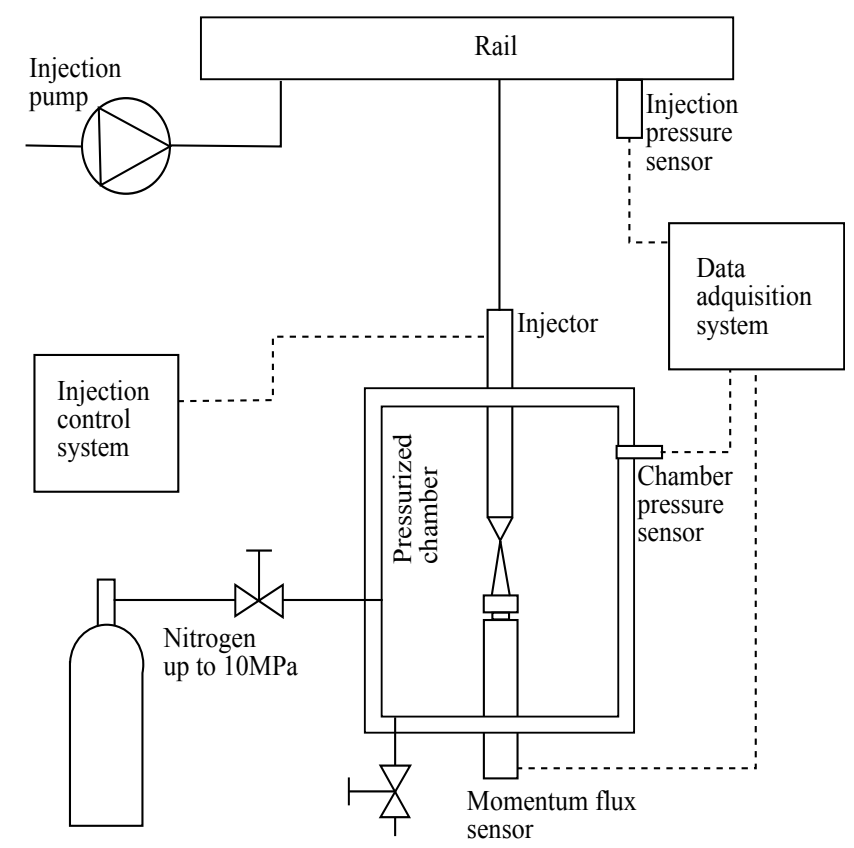

Figure 1: Spray momentum test rig.

\section{Spray visualization test rig}

This section describes the premises used for performing the visualization tests. A test rig pressurized with nitrogen is used for the visualization of the sprays at different operating conditions of injection and discharge pressures. Figure 2 shows a conceptual scheme of this installation.

The spray visualization is performed in a constant volume vessel, within which the nominal gas pressure is adjustable from 2 and $5 \mathrm{MPa}$, and the temperature between 15 and $40^{\circ} \mathrm{C}$. Nitrogen is continuously moving at very slow speed in order to evacuate the diesel released during successive injections and allow optical 


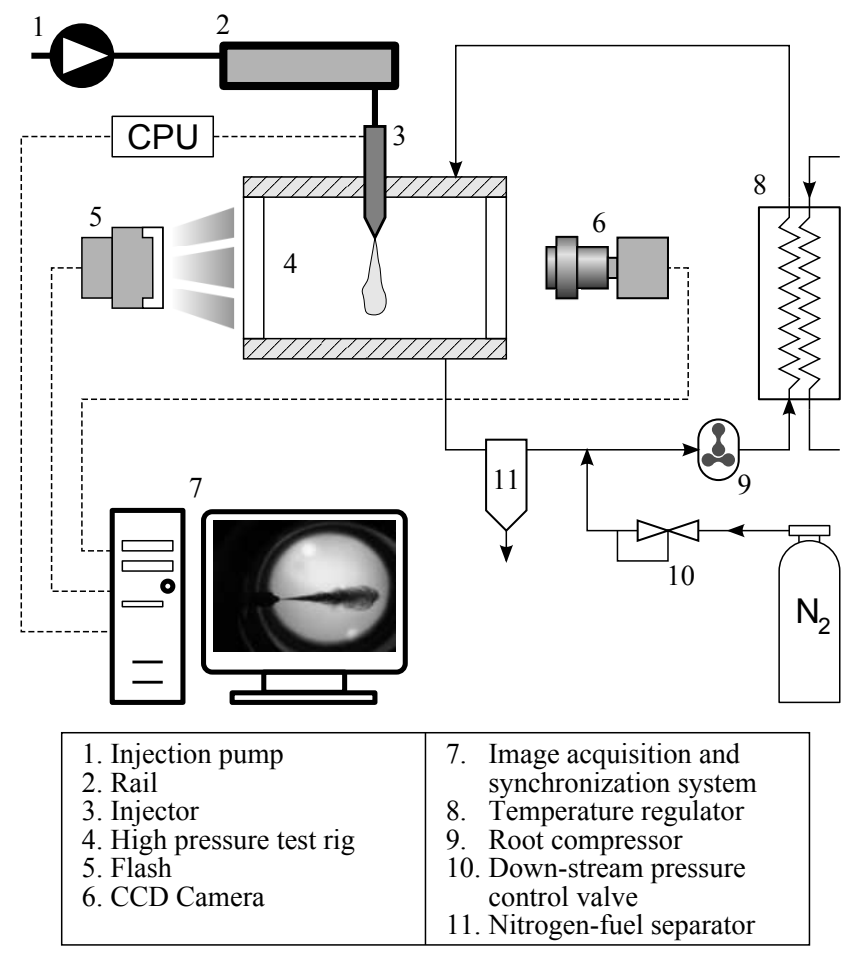

Figure 2: Conceptual scheme of the visualization test rig. 
access to remain clean as long as possible during the tests. The speed supplied to the nitrogen by a compressor is, however, sufficiently small to neglect any effect on the behavior of the spray. The frequency of injection is controlled and limited to a low value (one shot per second, or even less) to prevent rapid fouling of optical access, assuring the good quality of the images and thus, facilitating the task of processing them.

The diffuse backlighting illumination technique has been used for the visualization of the spray. In this technique, the camera is in one of the optical access, while the flash lighting is performed by the optical access opposite to the camera. Furthermore, an optical diffuser is placed between the light source and the test vessel.

Images are taken using a high-speed CMOS digital camera, obtaining images of 12 bits per color channel and a resolution of $1280 \times 1024$ pixels. The exposure time of this system is $5 \mu \mathrm{s}$.

\subsection{Image processing}

The fundamental step in image processing is the segmentation process. This process is performed after a first stage focused on filtering and substracting the background of images, which allows to discern what is spray and what is not, in all images taken Pastor et al. (2001). The problem of image segmentation in the frame of diesel sprays is particularly complex due to the biphasic nature of the spray (liquid-gas) that makes it very difficult to define its contours. However, the quality of the segmentation has a strong influence on the results obtained related to the macroscopic characteristics parameters of the spray in later stages of the post-process.

The segmentation algorithm used, based on the likelihood ratio test (LRT), uses the three RGB channels to produce a precise identification of the poorly defined contours as those observed in the case of injected sprays. It has been shown that this segmentation algorithm is quite insensitive to intensity variations between images, and results were better than others obtained with other tested algorithms Pastor et al. (2001).

Once the contour of the spray is isolated from the rest of the image, it is possible to determine the macroscopic parameters that can characterize the injection process. As it is known, the purpose of the injection process is to promote the air entrainment inside the fuel spray to get a good air-fuel mixture that facilitates the combustion process. The macroscopic parameters that can characterize this process are the penetration and angle of the spray. Figure 3 shows a graphical representation of the physical meaning of these parameters. 


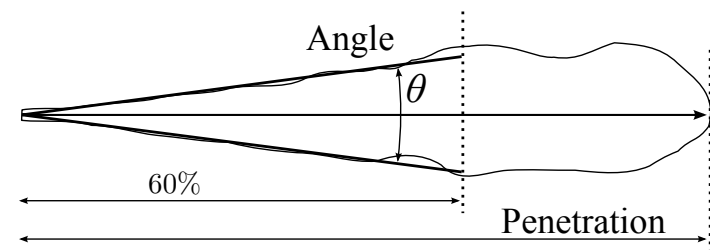

Figure 3: Relevant parameters of the spray obtained as a result of the visualization tests.

\section{Results}

\subsection{Data processing of the visualization tests}

Visualization tests are performed by taking photographs of the injected spray or sprays with an exposure time small enough to freeze spray in the image, obtaining a single photo for each injection. The instant at which the images are taken will vary throughout the test, in order to obtain the evolution of the spray from the nozzle exit until it exceeds the visual boundaries of the test rig.

In the present study, a total of five repetitions per time instant have been taken for each point tested, with a time interval between these instants of $25 \mu \mathrm{s}$.

Figure 4 shows an example of the sequence of images of the spray for the three nozzles in one of the conditions tested.

All images obtained are processed as explained in Section 5.1. Thus, the contour of the spray is firstly obtained and then, the macroscopic parameters of the spray, as the penetration or the spray angle, are extracted from this contour for further analysis.

The results obtained from these visualization tests are shown in the next section, starting with the penetration and continuing with the angle of the spray.

\subsection{Penetration results}

The temporal evolution of the spray penetration for all tests are shown in Figures 5, 6 and 7 for injection pressures of 30, 80 and $130 \mathrm{MPa}$ respectively. For each instant, the following figures were generated using the averaged value of the parameter under study. In addition, for each instant it has been also represented by a bar (Figure 5, upper-left) the mean value of the standard deviations of the data contained in each of the graphs.

In these figures, it is evident how the evolution of the spray penetration is divided into two zones as discussed in Section 2:

- Initial or transient zone. In this zone the spray penetration is linear with time, $S \propto t$. Furthermore, as can be seen, in this region it does not show 

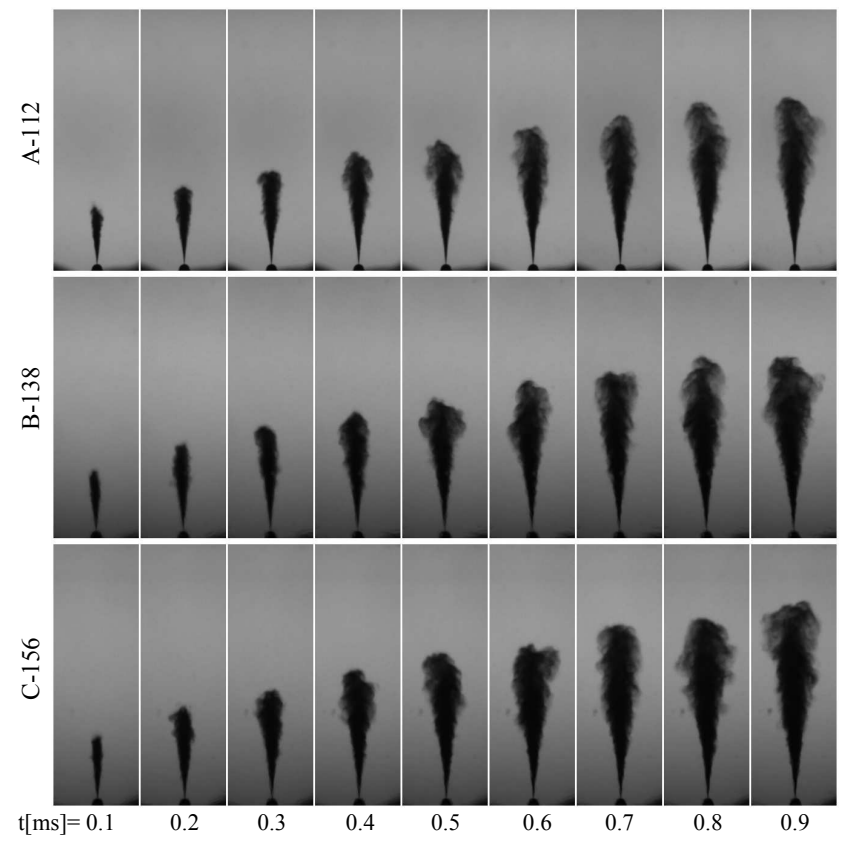

Figure 4: Images of the spray evolution for the point $p_{i}=80 \mathrm{MPa} \rho_{a}=40 \mathrm{~kg} / \mathrm{m}^{3}$.

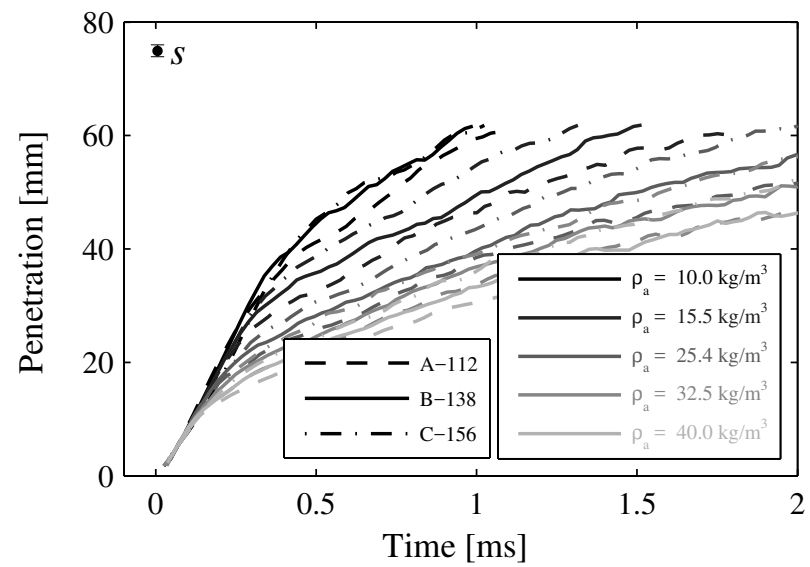

Figure 5: Spray penetration for points at the same injection pressure $p_{i}=30 \mathrm{MPa}$. 


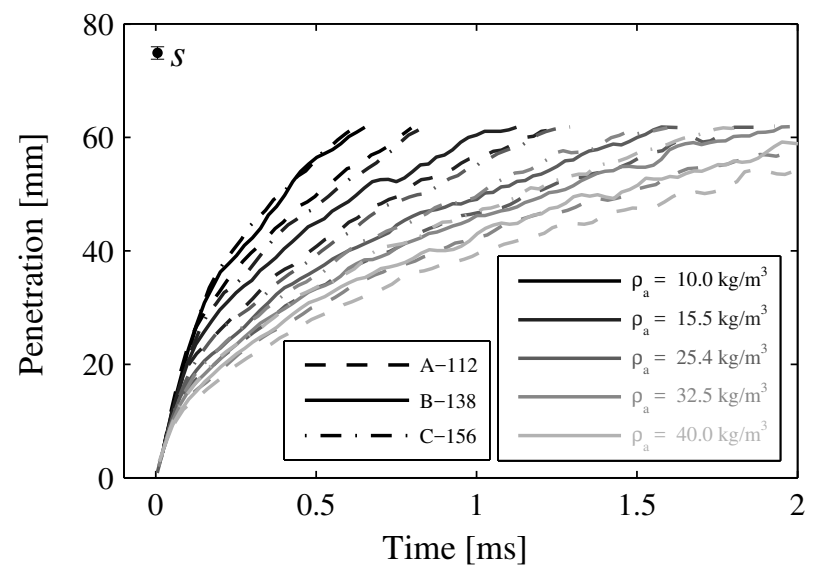

Figure 6: Spray penetration for points at the same injection pressure $p_{i}=80 \mathrm{MPa}$.

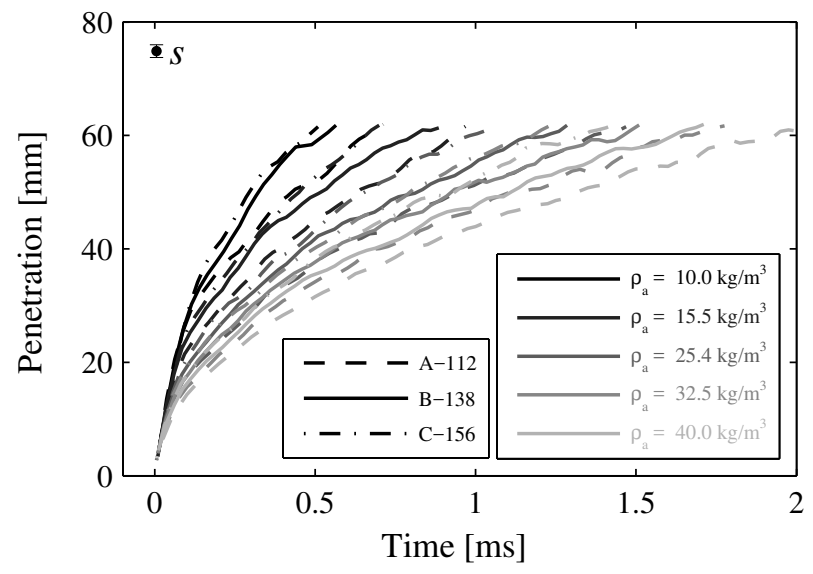

Figure 7: Spray penetration for points at the same injection pressure $p_{i}=130 \mathrm{MPa}$. 
any dependence on the diameter of the nozzle, and the influence of density seems also small Kostas et al. (2009).

- Fully developed zone. In this zone the spray penetration ceases to be linear with time and it becomes time dependent according to $S \propto t^{1 / 2}$. Contrarily to the initial zone, in this zone the spray penetration clearly depends on both the diameter of the nozzle and the gas density.

The next section shows a set of cases in which the effect of each of the parameters has been isolated: orifice diameter, gas density and injection pressure, in order to investigate their influence.

\subsubsection{Influence of nozzle geometry}

Figure 8 presents the spray penetration for the three nozzles for a particular test point. This figure corroborates the previous discussion. The transient zone is not dependent on hole diameter, so one might infer that depends on the exit velocity and not on the momentum flux or diameter Hiroyasu and Arai (1990). While in the fully developed spray zone a greater diameter, which in turn means greater momentum flux, results in a greater spray penetration.

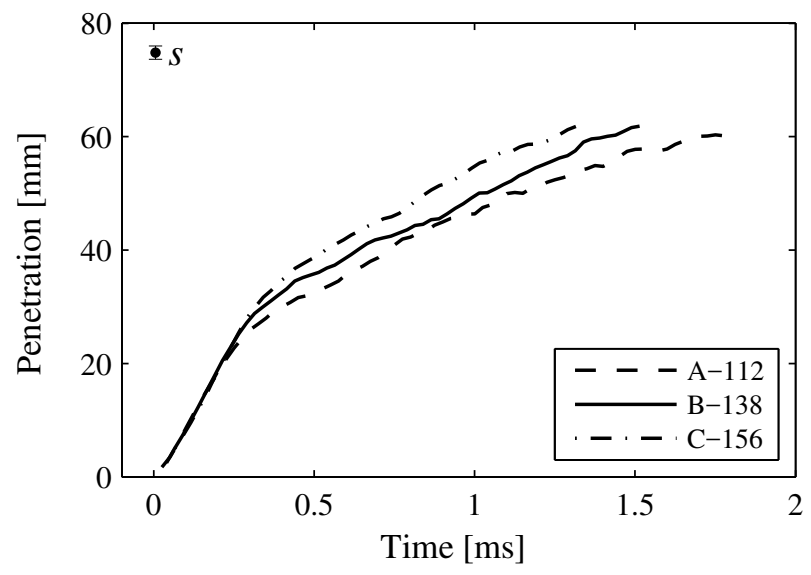

Figure 8: Comparison between nozzles in terms of spray penetration for the point $p_{i}=30 \mathrm{MPa}$ $\rho_{a}=15.5 \mathrm{~kg} / \mathrm{m}^{3}$.

\subsubsection{Influence of gas density}

Figure 9 illustrates the influence of gas density on penetration. In the fully developed spray zone the great influence of the density is appreciated and a higher 
penetration is observed for a lower density. In the transient zone the effect of density does not seem as important as in the fully developed zone, although here some influence is observed unlike what others authors have found Naber and Siebers (1996); Hiroyasu and Arai (1990).

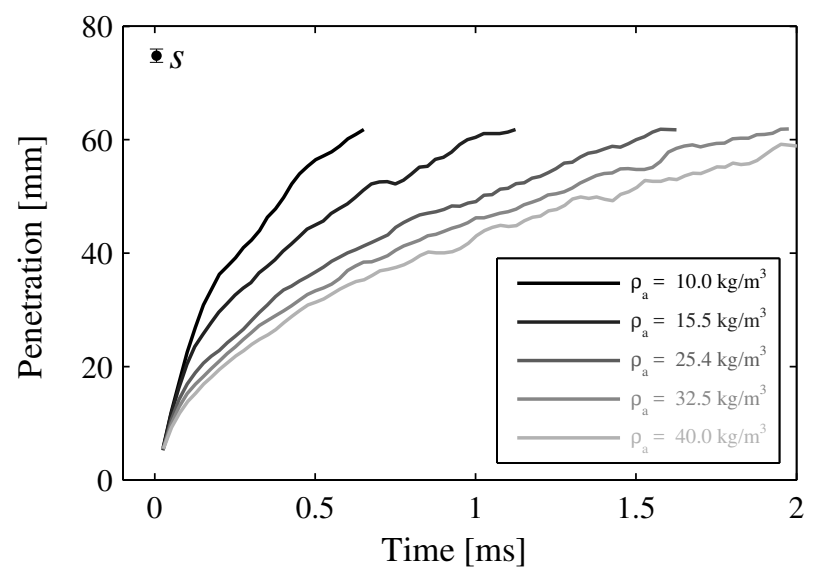

Figure 9: Comparison between different gas density levels in terms of spray penetration for the nozzle $B$ at $p_{i}=80 \mathrm{MPa}$.

\subsubsection{Influence of the injection pressure}

Figure 10 evidences the influence of injection pressure on spray penetration. As expected, penetration increases with injection pressure in both the initial and the fully developed spray zones.

\subsection{Spray angle results}

The results of spray angle versus time are discussed in this section. As with the penetration a set of cases have been selected to isolate the effect of each parameter: orifice diameter, gas density and injection pressure, facilitating the analysis of their influence.

The determination of the spray angle is a rather complicated task and it is subject to many uncertainties, so that, the values found may contain a relatively large error. Nevertheless, by having a large number of tests, it is possible to observe trends and extract conclusions.

In each of the figures presented in next sections, in addition to the signal of angle, it is represented the average deviation of the corresponding tests (lowerright). 


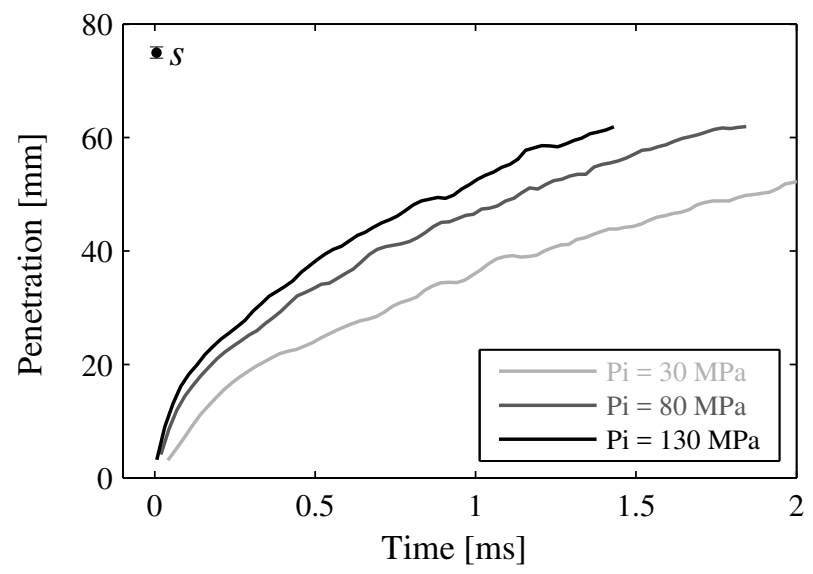

Figure 10: Comparison between different injection pressures in terms of spray penetration for the nozzle $C$ at $\rho_{a}=40 \mathrm{~kg} / \mathrm{m}^{3}$.

\subsubsection{Influence of geometry}

Figure 11 compares the results of the three nozzles at one particular injection condition. It seems that the diameter of the holes does not have a significant influence on the spray angle once it has stabilized, especially when compared with the effect of other parameters such as gas density, as discussed below.

\subsubsection{Influence of gas density}

Figure 12 shows the influence of density for one nozzle and one injection pressure. As expected, the increase in air density causes a significant increase in the spray angle Payri et al. (2005); Desantes et al. (2006).

\subsubsection{Influence of injection pressure}

In Figure 13 the influence of injection pressure is shown. The pressures of 80 and $130 \mathrm{MPa}$ has a wider spray angle compared to the case of $30 \mathrm{MPa}$, while for the pressure of $30 \mathrm{MPa}$ the spray angle is significantly smaller. This may be related to the flow regime inside the injection orifice, in which at $30 \mathrm{MPa}$ the flow regime was in a state of transition between laminar and turbulent conditions, whereas in the rest of points the turbulence is fully developed.

\section{Spray angle analysis}

In Figure 14 all results of spray angle are condensed. To obtain this data, a mean spray angle is calculated, taking special care to obtain a value as represen- 


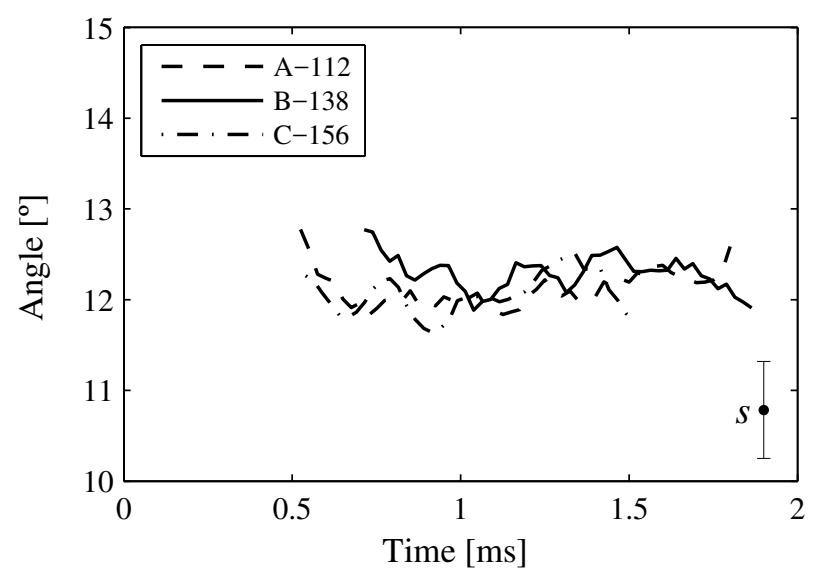

Figure 11: Comparison between nozzles in terms of spray angle for the point $p_{i}=30 \mathrm{MPa}$ at $\rho_{a}=15.5 \mathrm{~kg} / \mathrm{m}^{3}$.

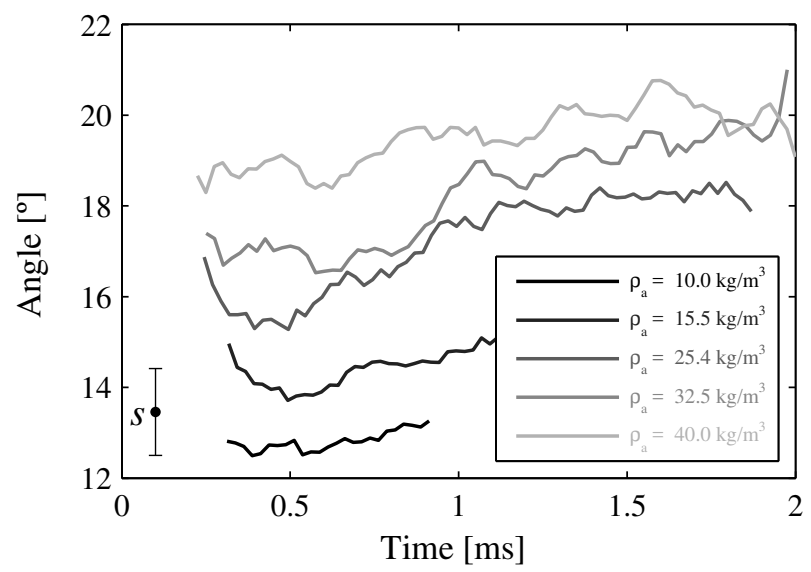

Figure 12: Comparison between different gas density levels in terms of spray angle for the nozzle $A$ a $p_{i}=130 \mathrm{MPa}$. 


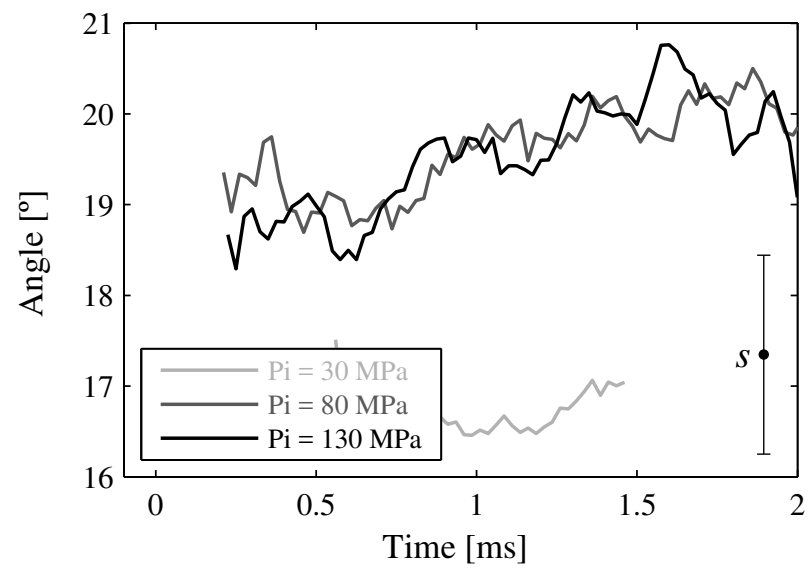

Figure 13: Comparison between different injection pressures in terms of spray angle for the nozzle $A$ at $\rho_{a}=40 \mathrm{~kg} / \mathrm{m}^{3}$.

tative and comparable as possible, so it is selected only the interval in which the angle is already stabilized (long time), and the same interval has been used for all nozzles in each pressure condition.

The relationship between the densities of gas and fuel $\rho_{a} / \rho_{f}$ has been selected as the abscissa axis, which is a parameter widely used in the study of spraysDesantes et al. (2005).

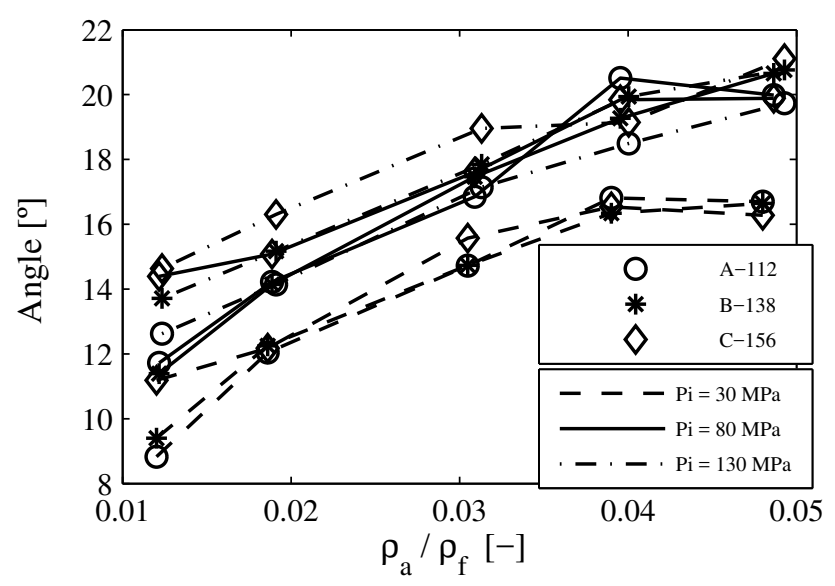

Figure 14: Variation of the spray angle $\theta$ in steady conditions.

This figure corroborates the previously observed effects: 
- Higher density implies a wider spray angle. This result is logical because the higher the gas density, the greater the opposition of the gas against the advance of the spray, causing it to open.

- The pressure of $30 \mathrm{MPa}$ produces a considerable smaller spray angle than the other pressures. This may be related to flow regime inside the injection orifice, since at $30 \mathrm{MPa}$ the flow regime was in a state of transition between laminar and turbulent conditions, contrarily to the rest of higher injection pressures, where the turbulence was developed. Or in other words, turbulence for pressure of $30 \mathrm{MPa}$ is less than for higher injection pressures. As it is known, turbulence is one of the factors promoting the opening of the spray, so the observed smaller spray angle for $p_{i}=30 \mathrm{MPa}$, where turbulence is lower, is reasonable.

- The influence of nozzle geometry on the spray angle is much lower than either of the two effects previously mentioned. Despite that, increasing the diameter (or reducing the $L / D$ ratio of the nozzle hole) slightly increases the spray angle.

\subsection{Correlations for the spray angle}

The following results will correlate the spray angle with the parameters identified as influential:

- Gas density, represented by the ratio of densities between the gas and fuel $\rho_{a} / \rho_{f}$.

- Turbulence intensity. The parameter that best characterizes the turbulence intensity is the area contraction coefficient $C_{a}$, which has values close to unity for fully developed turbulence, and decreases as turbulence decreases.

- Nozzle geometry. In this case the unique difference between the nozzles is the diameter or its dimensionless equivalent parameter, the length to diameter relation $L / D$.

Thus, the spray angle expressed in terms of the tangent of the half angle, can be correlated with the previous parameters by means of an exponential fit according to equation

$$
\tan \frac{\theta}{2}=\operatorname{cns}\left(\frac{\rho_{a}}{\rho_{f}}\right)^{a} C_{a}{ }^{b}\left(\frac{L}{D}\right)^{c},
$$


where a logarithmic transformation can be introduced to obtain the constant and exponents by a simply linear regression.

The following table summarizes the results of the fit according to equation (7). This table contains the value of the different adjustment factors, constant and exponents, plus the confidence interval for $\alpha=0.05$ and the P-value for each of these coefficients. The coefficient of determination of this adjustment is $R^{2}=0.968$.

\begin{tabular}{lcll}
\hline & Magnitude & \multicolumn{1}{c}{ CI } & \multicolumn{1}{c}{ P-value } \\
\hline$c n s$ & 0,8113 & $\pm 0,2448$ & 0,09197 \\
$a$ & 0,3316 & $\pm 0,02929$ & $5,908 \cdot 10^{-25}$ \\
$b$ & 7,319 & $\pm 1,275$ & $1,611 \cdot 10^{-14}$ \\
$c$ & $-0,1872$ & $\pm 0,1081$ & 0,001148 \\
\hline
\end{tabular}

As shown in the table the influence of the three factors are significant (P-value $<$ 0.05). However, the relevance of each one is different, being much higher for $\rho_{a} / \rho_{f}$ and $C_{a}$.

In fact, eliminating from the fit the term $L / D$ a good correlation is still obtained. So for the equation

$$
\tan \frac{\theta}{2}=\operatorname{cns}\left(\frac{\rho_{a}}{\rho_{f}}\right)^{a} C_{a}{ }^{b},
$$

the next fit is obtained, with a coefficient of determination $R^{2}=0.945$.

\begin{tabular}{lcll}
\hline & Magnitude & \multicolumn{1}{c}{ CI } & \multicolumn{1}{c}{ P-value } \\
\hline$c n s$ & 0,5924 & $\pm 0,1358$ & $1,133 \cdot 10^{-9}$ \\
$a$ & 0,3497 & $\pm 0,03562$ & $6,293 \cdot 10^{-23}$ \\
$b$ & 7,343 & $\pm 1,55$ & $4,252 \cdot 10^{-12}$ \\
\hline
\end{tabular}

\section{Analysis of the spray penetration}

In this section, the analysis of penetration is carried out. One drawback for this study on penetration is its time dependence. Therefore, in order to facilitate the analysis of results, in a first step, some parameters have been extracted to characterize each penetration test, achieving the independence of time.

To do this, knowing that the penetration is separated into two zones, it has been calculated for the initial zone the slope $m_{i}$ that produces the best fit to the equation $S=m_{i}\left(t-t_{o i}\right)$, and the parameter $m_{p}$ that best fit to equation $S=m_{p} \sqrt{t-t_{o p}}$ for the fully developed spray zone. In addition, it has also been obtained the time 
$t_{r}$ that separates these zones. Because of possible time lag between the penetration signal and the fit equations, temporal corrective terms $\left(t_{o i}\right.$ and $\left.t_{o p}\right)$ have been added to avoid the mistakes introduced by these lags in the fit. Figure 15 shows an example of how these parameters are obtained from one of the penetration measures.

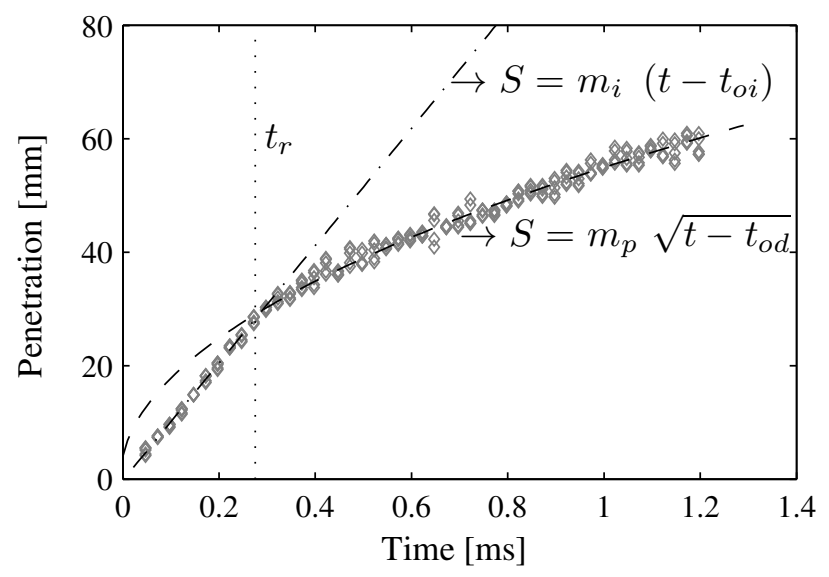

Figure 15: Calculation of the penetration parameters. (C nozzle, $\left.p_{i}=30 \mathrm{MPa}-\rho_{a}=15.5 \mathrm{~kg} / \mathrm{m}^{3}\right)$.

Obtaining these parameters is not always as simple as in the case of the figure, especially the determination of the slope of the initial zone because, depending on the conditions of injection, the number of time instants available for the fit generation may be poor. Because of this drawback, the initial values in the initial zone become less reliable the higher the gas density and the higher the injection pressure (see Figure 5, 6 and 7). The same is true for the transition time between both zones, because in these tests the initial zone is not easily distinguishable from the fully developed zone.

Once obtained the values for each of the tests, it is possible to proceed to the analysis of the results. First, the analysis of the fully developed spray is performed, and afterward the attention is focused on the initial zone.

\subsection{Fully developed spray}

The objective in this section is to obtain the value of the constant $k_{p}$ for each of the tests and performing the corresponding analysis. As shown in equation (4), the calculation of $k_{p}$ depends on the spray angle. Since the value of this angle is associated with significant dispersion, before including the values of the angle the penetration data will be analyzed without taking into account the spray angle. 
So firstly, the constant $C$ is found, which is defined as the dimensionless part of the equation (4), written below

$$
S=C \rho_{a}^{-1 / 4} \dot{M}^{1 / 4} t^{1 / 2} .
$$

Given this equation, the value of $C$ for each test can be calculated as

$$
C=\frac{m_{p}}{\rho_{a}^{-1 / 4} \dot{M}^{1 / 4}},
$$

where $m_{p}$ is obtained from the fit of the results of penetration, $\rho_{a}$ is known for each test and $\dot{M}$ is obtained from the momentum flux tests.

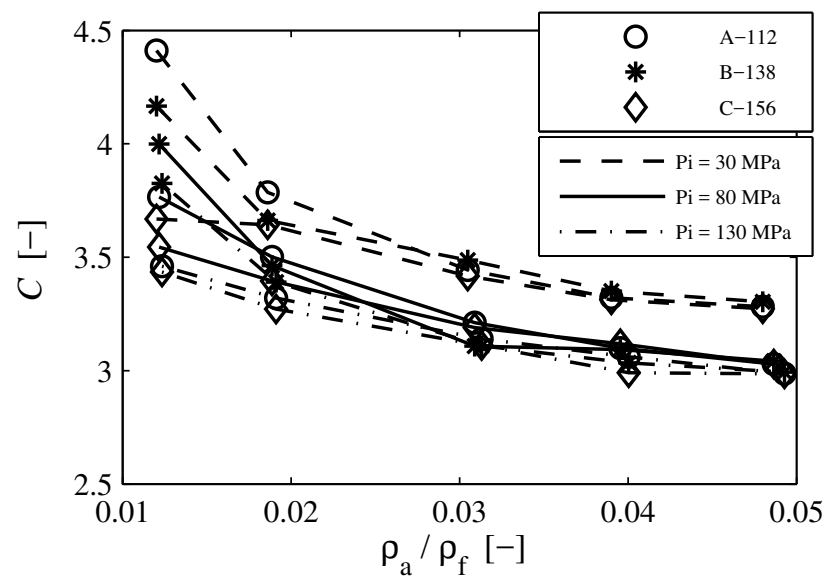

Figure 16: Penetration parameter $C$ for fully developed spray.

In Figure 16 the results for $C$ depending on the density ratio $\rho_{a} / \rho_{f}$ are presented. The trends observed in this diagram are closely related to the behavior of the spray angle already seen in Figure 14. Thus, the effects that increase the opening of the spray, as the density of gas in the chamber and the turbulence, cause a decrease in the constant $C$.

As was done with the spray angle, the constant $C$ can be correlated on the same parameters: the ratio of densities $\rho_{a} / \rho_{f}$, and the area contraction coefficient $C_{a}$. Thus, $C$ is correlated by the equation

$$
C=\operatorname{cns}\left(\frac{\rho_{a}}{\rho_{f}}\right)^{a} C_{a}{ }^{b},
$$

for which we obtain the following fit with a coefficient of determination $R^{2}$ of 0.962 . 


\begin{tabular}{lcll}
\hline & Magnitude & \multicolumn{1}{c}{ CI } & P-value \\
\hline cns & 2,013 & $\pm 0,04892$ & $2,543 \cdot 10^{-29}$ \\
$a$ & $-0,1137$ & $\pm 0,01283$ & $2,979 \cdot 10^{-21}$ \\
$b$ & $-3,344$ & $\pm 0,5586$ & $2,989 \cdot 10^{-15}$ \\
\hline
\end{tabular}

Unlike the results found for the spray angle, in the case of constant $C$ the influence of geometry was found not significant and was not included in the regression.

It is interesting to observe how the density of the gas in the chamber has a double influence on penetration. First, according to the equation (4) for the behavior of the fully developed spray $S \propto \rho_{a}{ }^{-0.25}$, on the other side causing further opening of the spray angle that ultimately leads to lower penetration according to the relation $S \propto \rho_{a}{ }^{-0.11}$. Adding these two effects the total influence of the density for the fully developed zone is around $S \propto \rho_{a}{ }^{-0.36}$.

From $C$, obtained using the results of penetration, and spray angle, it is possible to get information about $k_{p}$, according to the equation

$$
k_{p}=\frac{C}{(\tan (\theta / 2))^{-1 / 2}} .
$$

Before performing this calculation, it is interesting to plot the value of the denominator of the equation $(\tan (\theta / 2))^{-1 / 2}$, Figure 17 , and note the extreme similarity between this figure and that for the constant $C$ (Figure 16), taking into account that these graphs have a different source, the results of spray angle and penetration respectively. Even in the non-normal test points, as the nozzle $\mathbf{C}$ to $p_{i}=30 \mathrm{MPa}$ and the lowest density, one can observe the correlation between the two results.

The results of the penetration constant $k_{p}$ obtained from the calculation of the equation (12) have been represented in Figure 18. As might be expected in view of Figures 16 and 17, the value of $k_{p}$ for all tests is more or less constant, considering that the dispersion observed in the graph is entirely reasonable due to accumulated inaccuracies throughout the process of obtaining $k_{p}$.

Nevertheless, in Figure 18 one can see how $k_{p}$ still has a certain dependence

on the gas density that despite being small, $k_{p} \propto\left(\rho_{a} / \rho_{f}\right)^{0.038}$, it remains significant. This result may well be due to a faulty determination of the spray angle, overestimated at low-density or underestimated at high density.

The average of all tests is $k_{p}=1.244$. This value is close to the $k_{p}=1.26$ determined by Desantes and others in Desantes et al. (2006). This similarity between the value of $k_{p}$ obtained in both studies is certainly remarkable, since the 


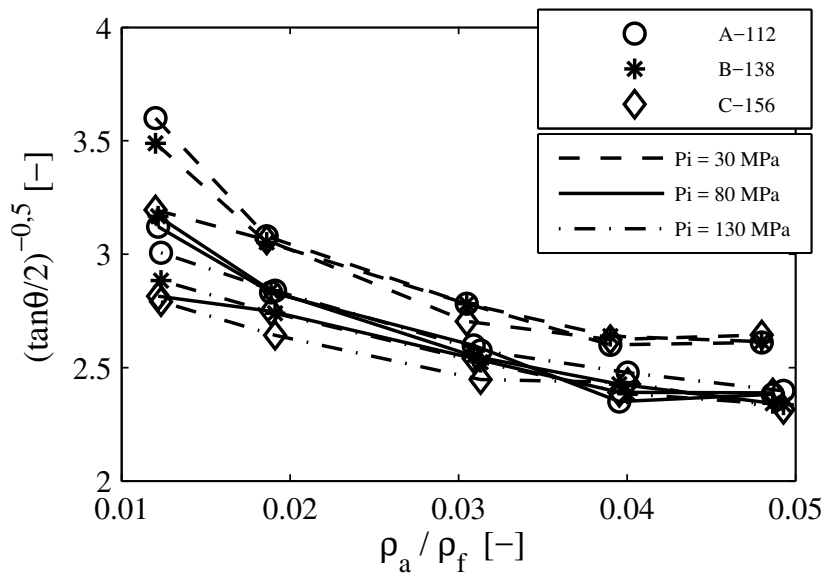

Figure 17: Variation of $(\tan (\theta / 2))^{-1 / 2}$ for fully developed spray.

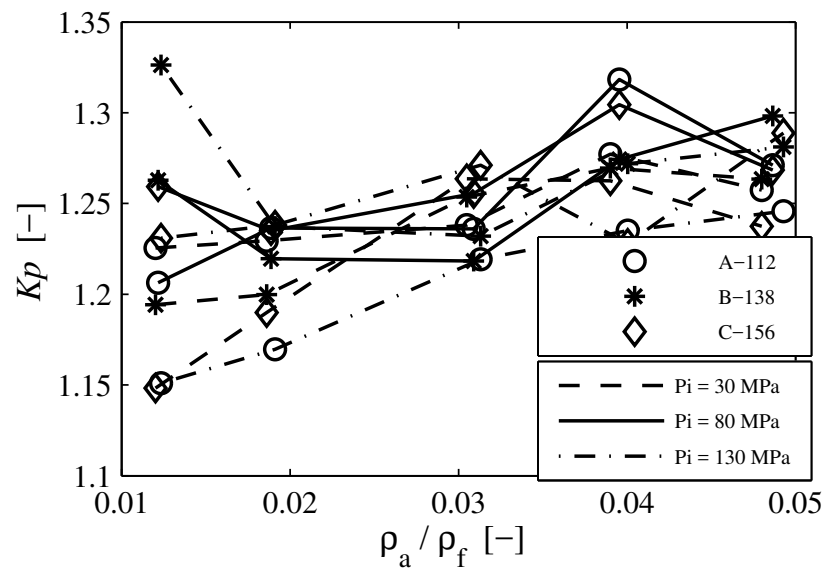

Figure 18: Penetration constant $k_{p}$ for fully developed spray. 
nozzles used in either study are quite different. In the work performed by Desantes et al. they used an axysimmetric configuration of cavitating nozzles with cylindrical holes, whereas in the present study, the nozzles are not cavitating as the holes are convergent. Given these results, the constant $k_{p}$ can be considered independent of both the injection conditions and the geometry of the orifice.

\subsection{Initial part of the spray}

The objective in this section is to obtain the value of the constant for the initial part of the spray $k_{i}$ for each of the tests and carry out the corresponding analysis. Given the equation (5), the value of $k_{i}$ can be calculated as:

$$
k_{i}=\frac{m_{i}}{u_{e f}}
$$

where $m_{i}$ is obtained from the fit of the results of penetration, and $u_{\text {ef }}$ comes from the internal flow characterization.

The results obtained for the constant $k_{i}$ are plotted in Figure 19. As it can

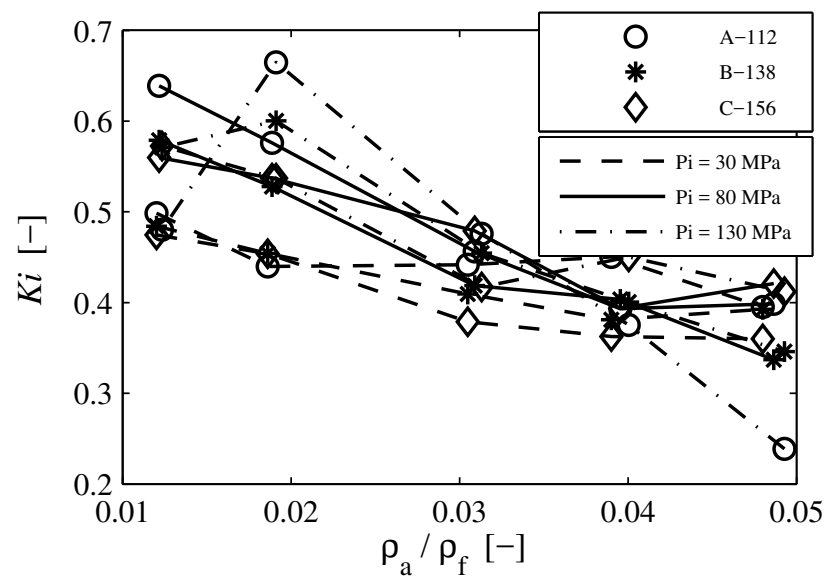

Figure 19: Penetration constant $k_{i}$ for the spray initial zone.

observed, the constant $k_{i}$ shows a clear downward trend when increasing gas density. And, although it is more difficult to identify because of the dispersion of results, one can also see a small influence of injection pressure, with $k_{i}$ greater when increasing the injection pressure. 
Considering these parameters, a correlation for the constant $k_{i}$ is suggested with the structure of the following equation,

$$
k_{i}=\operatorname{cns}\left(\frac{\rho_{a}}{\rho_{f}}\right)^{a} p_{i}^{b} .
$$

Introducing a linear regression of this correlation the values contained in Table 8.2 are obtained, with a coefficient of determination $R^{2}$ of 0.795 .

\begin{tabular}{lcll}
\hline & Magnitude & CI & \multicolumn{1}{c}{ P-value } \\
\hline cns & 0,1237 & $\pm 0,3029$ & $2,448 \cdot 10^{-017}$ \\
$a$ & $-0,2624$ & $\pm 0,05929$ & $2,926 \cdot 10^{-011}$ \\
$b$ & 0,08175 & $\pm 0,04909$ & 0,001667 \\
\hline
\end{tabular}

As might be expected in view of the results, the influence of the gas density is very significant. This result contrasts with those obtained by other authors as Hiroyasu and Arai Hiroyasu and Arai (1990) or Naber and Siebers Naber and Siebers (1996), who found no influence of the density of gas in the chamber on the initial part of penetration. However, recent work has confirmed this influence. Thus, in the work of Payri et al. Payri et al. (2008), the influence of gas density at the beginning of the spray is at a value of $\rho_{a}{ }^{-0.256}$ very similar to that obtained in the present work.

However, the influence of gas density on the initial part of the spray is smaller than on the fully developed spray, $S \propto \rho_{a}{ }^{-0.26}$ versus $S \propto \rho_{a}{ }^{-0.36}$.

The influence of injection pressure on $k_{i}$ is also significant, although to a much lesser degree than the gas density. What is striking in this case is how the trend is opposite to that found in the fully developed spray zone. The higher injection pressure, the greater the turbulence and thus it would be expected that, due to the increased spray angle, the initial penetration in the initial spray zone would decrease, as in the fully developed zone. However, the opposite happens, the lower injection pressure the lower the penetration. The explanation for this phenomenon may lie in the injector opening time, which will be slower at lower injection pressures Bermúdez et al. (2005) causing a slower evolution of the jet at the initial zone Naber and Siebers (1996); Payri et al. (2007).

Finally, it is also noticeable the non-influence of orifice geometry on this parameter $k_{i}$, giving validity to the equation (5) that models the behavior of the jet in its initial zone. 


\subsection{Transition time between the initial and the fully developed zones}

As a final step, the results for the transition time $t_{r}$ between the initial zone of the spray and the fully developed area will be analysed. This time has been determined experimentally from the penetration tests for each case.

In Figure 20, the results for the time $t_{r}$ obtained experimentally have been compiled.

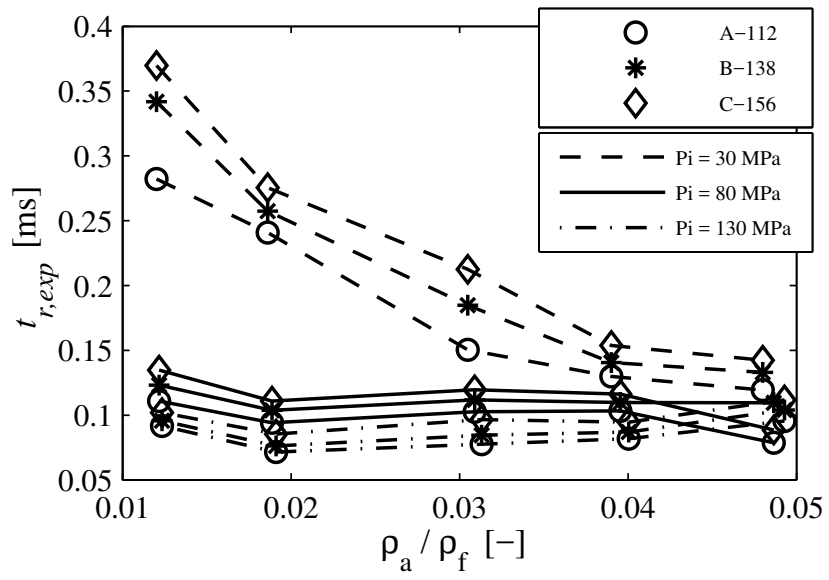

Figure 20: Transition time behavior $t_{r}$ obtained experimentally.

Analyzing these results, it is certainly complicated because $t_{r}$ is influenced by numerous parameters (see Equation (3) or (6)), being these in turn dependent on each other. In any case, one can see some trends, thus, $t_{r}$ will be greater for: lower injection pressure and larger diameter hole. In addition for the pressure of $30 \mathrm{MPa}$ a decrease of $t_{r}$ is observed when increasing the density of the chamber.

Finally, Figure 21 compares the time $t_{r, \text { exp }}$ obtained experimentally, with the time $t_{r, t e o}$ obtained by equation (6) derived from the penetration model.

As it can be seen the correspondence between the times is quite good, thus verifying the goodness of the equation (6).

\section{Conclusions}

This research work has the objective of giving insight on the relation between different relevant physical parameters and the macroscopic characteristics of diesel sprays. Different experimental data sources, such as injection rate, momentum flux and direct spray visualization have been combined to generate 


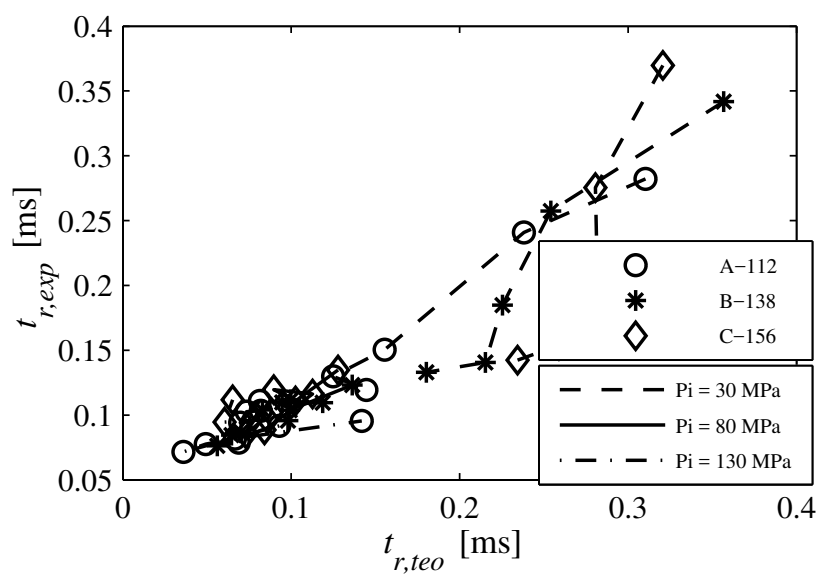

Figure 21: Equivalence between the transition time calculated experimentally and theoretically.

suitable results to perform a detailed analysis of diesel spray evolution in nonevaporative and non-reactive conditions. Finally, the most relevant knowledge gained with this investigation has been included in this section.

The spray angle, in the absence of cavitation mainly depends on the density of gas in the chamber and the degree of turbulence, being higher with increasing these two parameters. The effect of turbulence has been demonstrated, and even quantified, considering the internal flow results. Thus, the points with a lower area coefficient are those with lower degree of turbulence, and are precisely those points that have smaller spray angles.

From the results of this investigation, two zones have been identified in the behavior of the penetration: Initial or transient zone, which is characterized by its linearity with time $S \propto t$ and depend on the actual injection velocity. Furthermore, this initial zone depends on the density of gas in the chamber, decreasing the spray penetration as it increases, and on the injection pressure, the latter fact could be related to the higher opening speed of the injector observed increasing the injection pressure. Compared to the fully developed zone, this initial zone does not depend on hole diameter. Fully developed spray zone, which is characterized by being proportional to $S \propto \sqrt{t}$ and depend on the momentum flux. The other factors affecting the penetration in this zone are the density in the chamber and the spray angle, being smaller as they rise.

Additionally, it has been defined a model taking into account these two zones, in which the parameters obtained by the momentum flux measurement technique are basic (the momentum flux in the fully developed zone and the effective ve- 
locity in the initial zone), showing a good fit with the results. In the case of the fully developed zone it has been shown how the penetration constant $k_{p}$ does not depend on the operating point, and neither on the geometry of the nozzle.

\section{Acknowledgements}

This research has been funded in the frame of the Project "Caracterización experimental de la cavitación en el flujo interno e influencia sobre modelos de chorro diésel", Reference TRA2007-68006-C02-01, from MINISTERIO DE CIENCIA E INNOVACIÓN from Spain. The authors thank José Enrique del Rey for his collaboration in the experimental measurements.

\section{References}

Bermúdez, V., Payri, R., Salvador, F., Plazas, A., Jan. 2005. Study of the influence of nozzle seat type on injection rate and spray behaviour. Proceedings of the Institution of Mechanical Engineers, Part D: Journal of Automobile Engineering 219 (5), 677-689.

URL http://dx.doi.org/10.1243/095440705X28303

Desantes, J., Pastor, J., Payri, R., Pastor, J., 2005. Experimental characterization of internal nozzle flow and diesel spray behavior. part II: Evaporative conditions. Atomization And Sprays 15 (5), 517-543.

Desantes, J., Payri, R., Salvador, F., Gil, A., 2006. Development and validation of a theoretical model for diesel spray penetration. Fuel 85 (7-8), 910-917.

Hay, P., Jones, P., 1972. Comparaison of the various correlations for spray penetration. SAE Paper 720776.

Hiroyasu, H., Arai, M., 1990. Structures of fuel spray in diesel engines. SAE Paper 900475.

Kostas, J., Honnery, D., Soria, J., 2009. Time resolved measurements of the initial stages of fuel spray penetration. Fuel 88 (11), 2225-2237.

URL http://www.sciencedirect.com/science/article/ B6V3B-4WGDSBY-1/2/812cb9fbf42a36adf87930ff90d08c80

Macián, V., Bermudez, V., Payri, R., Gimeno, J., Mar. 2003a. New technique for determination of internal geometry of a diesel nozzle with the use of silicone methodology. Experimental Techniques 27 (2), 39-43. 
Macián, V., Payri, R., Margot, X., Salvador, F. J., 2003b. A cfd analysis of the influence of diesel nozzle geometry on the inception of cavitation. Atomization and Sprays 13, 579-604.

Naber, J. D., Siebers, D. L., 1996. Effects of gas density and vaporization on penetration and dispersion of diesel sprays. SAE Paper 960034.

Park, S. H., Kim, H. J., Suh, H. K., Lee, C. S., 2009a. Experimental and numerical analysis of spray-atomization characteristics of biodiesel fuel in various fuel and ambient temperatures conditions. International Journal of Heat and Fluid Flow 30 (5), 960-970, the 3rd International Conference on Heat Transfer and Fluid Flow in Microscale, The 3rd International Conference on Heat Transfer and Fluid Flow in Microscale.

URL http://www.sciencedirect.com/science/article/ B6V3G-4WB37BF-2/2/66ac5a20671ab3278ebcc1cf4422e5a0

Park, S. H., Kim, H. J., Suh, H. K., Lee, C. S., 2009b. A study on the fuel injection and atomization characteristics of soybean oil methyl ester (sme). International Journal of Heat and Fluid Flow 30 (1), 108-116.

URL http://www.sciencedirect.com/science/article/ B6V3G-4V69JFH-1/2/7a29c3c94d69eaffd2bdb2cb0129b26b

Park, S. H., Suh, H. K., Lee, C. S., Aug. 2009c. Effect of bioethanol-biodiesel blending ratio on fuel spray behavior and atomization characteristics. Energy \& Fuels 23 (8), 4092-4098.

URL http://dx.doi.org/10.1021/ef900068a

Pastor, J., Arrègle, J., Palomares, A., 2001. Diesel spray images segmentation using a likelihood ratio test. Applied Optics 40 (17), 2876-2885.

Payri, R., Ruiz, S., Salvador, F., Gimeno, J., 2007. On the dependence of spray momentum flux in spray penetration. Journal of Mechanical Science and Technology 21 (7), 1100-1111.

Payri, R., Salvador, F., Gimeno, J., De la Morena, J., 2008. Macroscopic behavior of diesel sprays in the near-nozzle field. SAE International Journal of Engines 1 (1), 528-536, sAE Paper 2008-01-0929 Editor: SAE International.

Payri, R., Salvador, F., Gimeno, J., de la Morena, J., 2009. Study of cavitation phenomena based on a technique for visualizing bubbles in a liquid pressurized chamber. International Journal of Heat and Fluid Flow 30 (4), 768-777. 
Payri, R., Salvador, F. J., Gimeno, J., Soare, V., Nov. 2005. Determination of diesel sprays characteristics in real engine in-cylinder air density and pressure conditions. Journal Of Mechanical Science And Technology 19 (11), 20402052.

Ramírez, A., Som, S., Aggarwal, S., Kastengren, A., El-Hannouny, E., Longman, D., Powell, C., 2009. Quantitative x-ray measurements of high-pressure fuel sprays from a production heavy duty diesel injector. Experiments in Fluids 47 (1), 119-134.

Reitz, R., Bracco, F., 1979. On the dependence of spray angle and other spray parameters on nozzle design and operating conditions. SAE Paper 790494.

Ruiz, F., 1998. Turbulence inside a cavitating injector orifice: a different animal. ILASS-Americas, 133-137.

Som, S., Aggarwal, S., 2009. Assessment of atomization models for diesel engine simulations. Atomization and Sprays 19 (9), 885-903.

Soteriou, C., Zuelch, S., Lambert, M., Passerel, D., 2006. The flow characteristics of high efficiency diesel nozzles with enhanced geometry holes. In: THIESEL 2006 Conference on Thermo and Fluid-dynamic Processes in Diesel Engines.

Wakuri, Y., Fujii, M., Amitani, T., Tsnumeya, R., 1960. Studies of the penetration of a fuel spray in a diesel engine. Bull. JSME 3 (9), 123-130.

Wan, Y., Peters, N., 1999. Scaling of spray penetration with evaporation. Atomization and Sprays 9 (2), 111-132.

\section{Appendix A. Internal flow data}

In the next graphs, the internal flow parameters used in this article have been represented: momentum flux, effective velocity and area coefficient. 


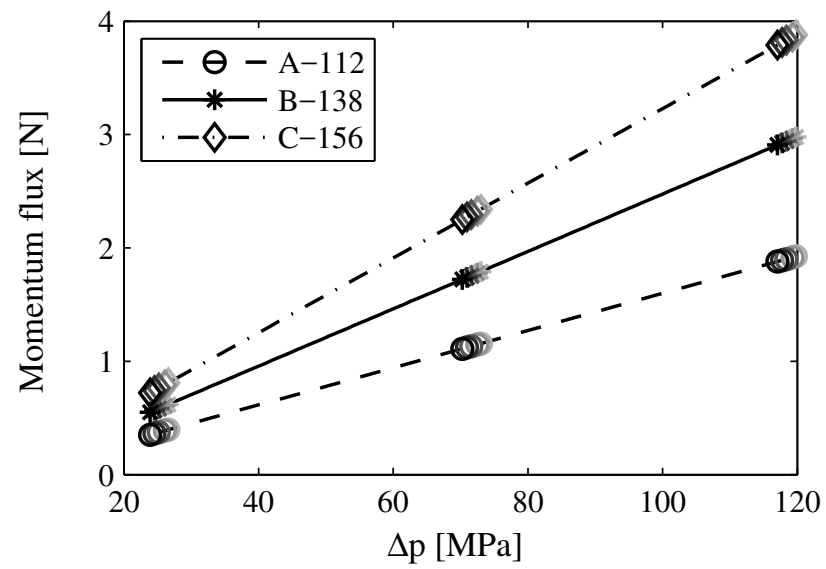

Figure A.22: Momentum flux versus pressure drop.

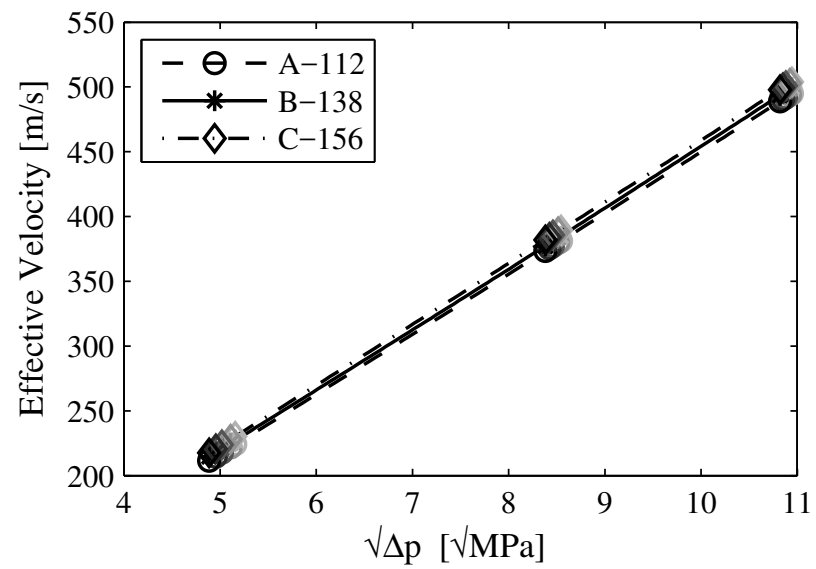

Figure A.23: Effective velocity versus square root of the pressure drop. 


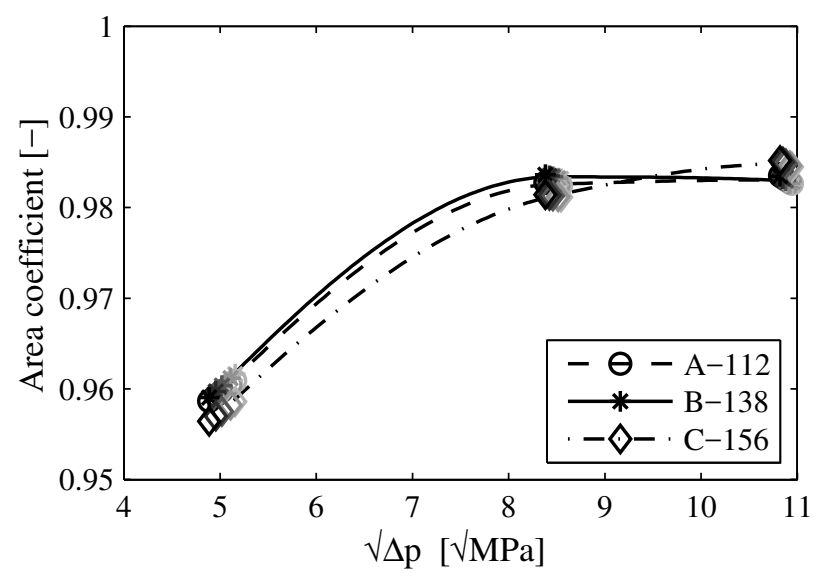

Figure A.24: Area coefficient versus square root of the pressure drop.

R.Payri, F.J.Salvador, J.Gimeno, R.Novella, "Flow regime effects on non-cavitating injection nozzles over spray behavior", International Journal of Heat and Fluid Flow, (2011), Vol. 32, pp. 273-284, doi:10.1016/j.ijheatfluidflow.2010.10.001 